\title{
Optimization of Process Parameters for Preparing Straw Fiber from Corn Stalk Rind
}

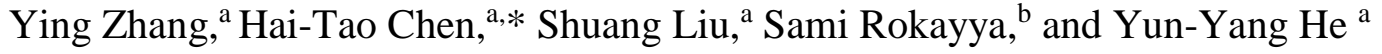 \\ To study the influence of process parameter changes on the properties of \\ raw material obtained from corn rind, a central composite design (CCD) \\ methodology with four factors and five levels was applied to statistically \\ optimize the parameters. The stalk size, soaking time, working \\ temperature, and processing speed were selected as influencing factors. \\ The available fiber ratio, initial beating degree, and fiber aspect ratio were \\ chosen as indicators. Response surface analysis methodology was \\ employed for optimization. The results showed that the optimal range of \\ parameters were as follows: 8 to $13 \mathrm{~cm}$ for the stalk size, $18 \mathrm{~h}$ for the \\ soaking time, $60^{\circ} \mathrm{C}$ for the working temperature, and 98 to $112 \mathrm{r} \cdot \mathrm{min}^{-1}$ for \\ the processing speed. In this optimal condition, the available fiber ratio \\ was higher than $95 \%$, initial beating degree was greater than $11^{\circ} \mathrm{SR}$, and \\ fiber aspect ratio was greater than 50 . The results could be applied to \\ design and optimize the D200 type stalk fiber preparation machine and the \\ process of making raw material.
}

Keywords: Corn stalk; Rind-pith separation; Raw material; Optimization; Mulching film

Contact information: a: Northeast Agricultural University, No. 600 Changjiang Road, Xiangfang District, Harbin, Heilongjiang Province, China; b: Department of Food Science and Nutrition, Taif University, Taif 888, Kingdom of Saudi Arabia; *Corresponding author: zhangying0604@ 163.com

\section{INTRODUCTION}

Agricultural crop residues are relatively inexpensive and produced in billions of tons around the world (Sain and Panthapulakkal 2005). Examples include cotton stalk, corn stalk, and cereal stalk. Corn is the most widely grown crop in several countries. The harvesting of corn is accompanied by accumulation of a large amount of stalk (Kadam and McMillan 2003). In typical agricultural practices, the corn stalk has been recovered to prepare feedstuff and bedding for livestock, or it has been incinerated in the field (DelgadoAguilar et al. 2018), causing environmental pollution. Therefore, the efficient utilization of corn stalk has become a research focus (Reddy and Yang 2005; Zhong et al. 2011). Biomass-based resources such as corn stalk can be used as substitutes for various nonrenewable materials that have negative impact on the environment (Fitzpatrick et al. 2010; Fatehi et al. 2013). Using a mechanical method to make corn stalk into fiber and then using fiber to make mulching film to return to soil can be regarded as a virtuous cycle, leading to favorable outcomes. A corn stalk can be used as a whole piece, but it also can be divided into rind and pith for various uses (He et al.2016; Chen and Wang 2017). Saijonkari-Pahkala (2008) found that the heterogeneity of the biomass affects the quality of the pulp, when using the whole corn stalk. The fibers from the pith are generally regarded as being too small to be ideal for papermaking. The whole corn stalk contains $20 \%$ pith, which means less papermaking fiber content. In addition, since the pith reduces the drainage rate of pulp, washing and dewatering become difficult, which makes it difficult to form paper (Byrd and Hurter 2005; Wang and Chen 2013). Therefore, the pith is usually 
separated from corn stalk before re-processing. After separation, the corn stalk rind can be used as excellent raw materials in boards or papermaking or plant fiber mulching film, while the corn stalk pith has been used as good feed for ruminants. Researchers have used corn stalk rind as a straw fiber to compound a mulching film and found the fiber mulching film can inhibit grass growth, increase crop yield, and increase soil water content when it is laid on farmland (Liu et al. 2017; Zhang et al. 2014). Such applications are a kind of substitute for plastic mulching film (Haapala et al. 2014). Accordingly, in the present article the term "mulching film" will also be used when describing a substitute product prepared from corn stalk rind. The excellent properties of the fibers that make up the biomass-based sustainable materials also determine the quality of the materials themselves. Improving the fiber properties and improving the processing technology can save costs and use chemical additives in the subsequent work. Therefore, the research on how to make corn straw fiber with better excellent performance provides a solid foundation for the manufacture of mulching film.

In order to explore corn straw fiber with better performance, main parameters for pilot-scale production equipment and main influencing factors of experiment conditions were optimized. This study can be a reference for the manufacture and improvement of fully degradable corn stalk fiber mulching film, which meets the requirements of organic cultivation.

\section{EXPERIMENTAL}

\section{Materials}

Dongnong 253 corn stalks were obtained from Xiangyang test base of Northeast Agricultural University (Harbin, China) in 2018.

\section{Equipment and Instrument}

The following were used in the study: D200 type straw fiber preparation machine, (25 to $120{ }^{\circ} \mathrm{C}$ working temperature, zero to $140 \mathrm{r} / \mathrm{min}$ processing speed) developed by Northeast Agricultural University; corn stalk separating unit (custom made) developed by Northeast Agricultural University; ZT4-00 type beater, (Zhongtong Test Equipment Co. Ltd., China); PlusV3.5.0 LeicaQwin optical microscope, (Leica Microsystems Co. Ltd., Germany); ZCX-15PA type pattern copying device (Changchun Yueming Scientific Instruments Co. Ltd., China); ZBSX-92A type vibration sieve machine (Zhejiang Xinda Instruments Factory, China); ZJG-100 Schober's beating degree instrument (Changchun Yueming Scientific Instruments Co. Ltd., China); DRK101A paper products quality detector (Jinan Nake Industry and Trade Co. Ltd., China); JA5003B type electronic balance (0.001 g precision Shanghai Jingke Tianmei Scientific Instruments Co. Ltd., China); YHG400-BS-II rapid far-infrared oven thermostat (Shanghai Huyueming Scientific Instruments Co. Ltd., China); GBJ-A fiber standard dissociation machine (Wuhan Graimo Test Equipment Co. Ltd., China); WG-2B centrifuge (Xingtai Haocheng Technology Development Co. Ltd., China); ZUS-4 type paper thickness tester (Changchun Yueming Small Test Machine Co. Ltd., China); and a straw rubbing and cutting machine (Harbin Longmu Machinery Company, China). 


\section{Methods}

A central composite design (CCD) methodology of four factors with five levels was applied to determine the effects of various indicators. Stalk size $(A)$, soaking time $(B)$, working temperature $(C)$, and processing speed $(D)$ were selected as factors. Available fiber ratio $\left(y_{1}\right)$, initial beating degree $\left(y_{2}\right)$, and fiber aspect ratio $\left(y_{3}\right)$ were determined as indicators. The level code-based table of indicators of the test factors is shown in Table 1.

Table 1. Experimental Factors Coded by Levels

\begin{tabular}{|c|c|c|c|c|}
\hline Level & $\begin{array}{c}\text { Stalk Size } \\
A(\mathrm{~cm})\end{array}$ & $\begin{array}{c}\text { Soaking Time } \\
B(\mathrm{~h})\end{array}$ & $\begin{array}{c}\text { Working Temperature } \\
C\left({ }^{\circ} \mathrm{C}\right)\end{array}$ & $\begin{array}{c}\text { Processing } \\
\text { Speed } \\
D(\mathrm{r} / \mathrm{min})\end{array}$ \\
\hline+2 & 13 & 24 & 90 & 120 \\
\hline+1 & 10 & 18 & 80 & 110 \\
\hline 0 & 7 & 12 & 70 & 100 \\
\hline-1 & 4 & 6 & 60 & 90 \\
\hline-2 & 1 & 0 & 50 & 80 \\
\hline
\end{tabular}

\section{Procedure}

Corn stalk was separated into corn stalk rind and corn stalk pith. The prepared corn stalk rind was then cut into segments in test-required segments sizes, as shown in Table 1. The cut corn stalk rind specimens were soaked with tap water at room temperature for specific times, as required in the program. Under the test condition and program, straw fiber mulching film raw materials (fibers) was produced. The soaked corn stalk rind was fed at the rate of $0.414 \mathrm{~kg} / \mathrm{min}$ to obtain fibers, and then the fibers were dried in air. The dried fiber was sieved using sieves of various mesh numbers for obtaining dispersed fibers suitable for the next step in processing. Available fiber ratio was measured as follows: Fiber was dried in air, then was sieved through different mesh sizes and then oven dried. The fiber percentage content under different mesh numbers was calculated $(<0.25 \mathrm{~mm}$, 0.25 to $0.5 \mathrm{~mm}, 0.5$ to $1 \mathrm{~mm}, 1$ to $2 \mathrm{~mm}$ and 2 to $10 \mathrm{~mm}$ ), and the proportion of fiber, a mesh number less than $10 \mathrm{~mm}$ was calculated as available fiber ratio. It can be defined by Eq. 1(Han 2011),

$$
X=\frac{m_{1}}{m_{2}}
$$

where $m_{1}(\mathrm{~kg})$ is the dry matter weight of the fiber, whose mesh number is below $10 \mathrm{~mm}$, and $m_{2}(\mathrm{~kg})$ is the whole weight of fiber dry matter:

The fiber refining process was carried out using GB/T 24325-2009. The SchopperRiegler method (GB/T 3332-2004) was used to measure the initial beating degree of the fibers, the numerical average of directly read value was taken as a result.

A conventional optical microscopy assay (GB/T10336-1989) was used to measure the aspect ratio of prepared fiber following Eqs. 2 and 3 (Han 2011),

$$
\begin{aligned}
& X=\frac{L}{W} \\
& X_{\mathrm{n}}=\frac{\sum_{i=1}^{n} X_{i}}{n}
\end{aligned}
$$

where $L(\mathrm{~mm})$ is the length of a single fiber; $W(\mathrm{~mm})$ is the width of the single fiber; $n$ is the number of fibers; $X_{\mathrm{i}}$ is the aspect ratio of a single fiber with number; and $X_{\mathrm{n}}$ is the average aspect ratio of fibers. 
Design-Expert software (Version 6.0.10, State-Ease Inc., USA) was used for statistical data analysis, so as to obtain the influence of factors on indexes.

\section{RESULTS AND DISCUSSION}

\section{Experimental Data}

Experimental data are shown in Table 2.

\section{Regression Model Equations}

According to ANOVA for Response Surface 2FI Models, the final equation in terms of coded factors are shown in Eqs. 4, 5, and 6.

$$
\begin{aligned}
& y_{1}=0.86+2.67 \times 10^{-4} A+2.99 \times 10^{-2} B-7 \times 10^{-2} C+3.6 \times 10^{-3} D+1.78 \times 10^{-2} A B+3.83 \times 10^{-} \\
& { }^{3} A C+1.5 \times 10^{-2} A D+2.42 \times 10^{-2} B C+4.56 \times 10^{-2} B D+1.37 \times 10^{-2} C D \\
& y_{2}=10.22+0.64 A-0.47 B-0.41 C+0.11 D+0.37 A B+0.13 A C-0.12 A D-0.78 B C-0.51 B D+0.7 C D
\end{aligned}
$$

$y_{3}=51.51+1.33 A+0.47 B+0.5 C+1.38 D+0.44 A B-1.05 A C-0.81 A D+0.18 B C-0.3 B D-1.44 C D$

\section{Tables of Variance Analyses for Regression Models}

Variance analysis results are shown in Tables 3, 4, and 5. It was found that the pvalues of available fiber ratio, initial beating degree, and fiber aspect ratio $(\mathrm{p}=0.0058$, $0.0158,0.0006)$ of these models were less than 0.05 or 0.01 , which indicated that these models were significant $(\mathrm{p}<0.05)$ or highly significant $(\mathrm{p}<0.01)$. Because insignificant lack of fit $(\mathrm{p}=0.3180,0.1491,0.6657)$ in models were more than 0.1 , these models showed insignificant lack of fit $(\mathrm{p}>0.1)$. Therefore, these models have a favorable fitting degree and a minor experimental error, and they were all judged to be appropriate models. As a result, the models could be used to evaluate the influential law of experimental factors on indicators.

\section{Influences of Factors on Available Fiber Ratio}

The p-value of $C$ in Table 3 is 0.0001 , which indicated that $C$ was highly significant relative to model response. Based on the p-values of $A, B, C$, and $D$, the sequence for the 4 factors influencing the available fiber ratio was $C>B>D>A$, that is, working temperature $>$ soaking time $>$ processing speed $>$ stalk size.

The working temperature of the stalk fiber preparation machine was the primary influencing factor on the available fiber ratio because of the softening effect of temperature on straw fibers. The temperature affects the degradation of volatile acids and polysaccharides in fiber cells, making the fiber cells easier to be destroyed, and the mechanical force exerted by the machine makes fiber cells easier to separate from the fiber bundles.

The p-value of the corresponding regression model for $B D$ was 0.0226 , which revealed that factors refer to the cross term had significant interaction influence on available fiber ratio. 
Table 2. Experimental Data

\begin{tabular}{|c|c|c|c|c|c|c|c|}
\hline No. & $\begin{array}{l}\text { Stalk } \\
\text { Size } \\
A(\mathrm{~cm})\end{array}$ & $\begin{array}{c}\text { Soaking } \\
\text { Time } \\
B(\mathrm{~h})\end{array}$ & $\begin{array}{c}\text { Working } \\
\text { Temperature } \\
C\left({ }^{\circ} \mathrm{C}\right)\end{array}$ & $\begin{array}{l}\text { Processing } \\
\text { Speed } \\
D(\mathrm{r} / \mathrm{min})\end{array}$ & $\begin{array}{c}\text { Available } \\
\text { fiber } \\
\text { ratio } \\
y_{1}(\%)\end{array}$ & $\begin{array}{c}\text { Initial } \\
\text { Beating } \\
\text { Degree } \\
y_{2} \text { ('SR) }\end{array}$ & $\begin{array}{c}\text { Fiber } \\
\text { Aspect } \\
\text { Ratio } \\
y_{3}\end{array}$ \\
\hline 1 & -1 & -1 & -1 & -1 & 94.91 & 9.58 & 44.64 \\
\hline 2 & 0 & 0 & 0 & 0 & 90.80 & 9.76 & 54.46 \\
\hline 3 & 1 & 1 & 1 & 1 & 95.59 & 10.98 & 50.29 \\
\hline 4 & 1 & 1 & 1 & -1 & 71.93 & 8.16 & 54.36 \\
\hline 5 & 0 & 0 & 0 & 0 & 80.57 & 10.26 & 55.63 \\
\hline 6 & 1 & -1 & 1 & -1 & 67.77 & 11.35 & 51.53 \\
\hline 7 & 0 & 0 & 0 & 0 & 95.55 & 8.85 & 49.87 \\
\hline 8 & 0 & -2 & 0 & 0 & 84.65 & 9.57 & 50.60 \\
\hline 9 & 0 & 0 & 0 & 0 & 76.80 & 10.28 & 51.93 \\
\hline 10 & -1 & 1 & -1 & -1 & 84.58 & 12.52 & 44.87 \\
\hline 11 & 0 & 0 & 0 & 0 & 95.70 & 8.63 & 51.46 \\
\hline 12 & 1 & -1 & 1 & 1 & 63.61 & 11.46 & 50.54 \\
\hline 13 & 0 & 0 & 0 & -2 & 90.92 & 9.46 & 50.31 \\
\hline 14 & -2 & 0 & 0 & 0 & 96.38 & 8.13 & 48.77 \\
\hline 15 & -1 & 1 & -1 & 1 & 94.46 & 8.51 & 49.94 \\
\hline 16 & 0 & 0 & 0 & 0 & 85.08 & 8.91 & 51.55 \\
\hline 17 & 1 & -1 & -1 & -1 & 87.96 & 11.55 & 50.34 \\
\hline 18 & -1 & 1 & 1 & 1 & 80.63 & 7.25 & 52.01 \\
\hline 19 & -1 & -1 & -1 & 1 & 81.63 & 11.87 & 52.51 \\
\hline 20 & -1 & 1 & 1 & -1 & 68.18 & 6.56 & 49.06 \\
\hline 21 & 0 & 0 & 0 & 0 & 88.30 & 10.63 & 51.73 \\
\hline 22 & 0 & 0 & 0 & 0 & 93.90 & 10.82 & 51.64 \\
\hline 23 & 2 & 0 & 0 & 0 & 90.00 & 11.53 & 52.08 \\
\hline 24 & 0 & 0 & -2 & 0 & 96.83 & 11.56 & 50.65 \\
\hline 25 & 0 & 0 & 0 & 0 & 80.83 & 8.92 & 48.38 \\
\hline 26 & 0 & 0 & 0 & 0 & 92.40 & 9.86 & 51.49 \\
\hline 27 & -1 & -1 & 1 & -1 & 74.71 & 9.59 & 49.01 \\
\hline 28 & 1 & -1 & -1 & 1 & 90.00 & 11.25 & 55.27 \\
\hline 29 & 1 & 1 & -1 & 1 & 91.82 & 10.53 & 56.92 \\
\hline 30 & 0 & 0 & 2 & 0 & 76.40 & 11.52 & 54.53 \\
\hline 31 & 0 & 2 & 0 & 0 & 95.35 & 10.35 & 55.39 \\
\hline 32 & 0 & 0 & 0 & 0 & 98.28 & 11.58 & 51.47 \\
\hline 33 & 1 & 1 & -1 & -1 & 89.45 & 12.47 & 50.50 \\
\hline 34 & -1 & -1 & 1 & 1 & 65.61 & 13.19 & 52.36 \\
\hline 35 & 0 & 0 & 0 & 2 & 83.30 & 9.13 & 54.12 \\
\hline 36 & 0 & 0 & 0 & 0 & 91.05 & 11.38 & 54.09 \\
\hline
\end{tabular}

\section{Influences of Factors on Initial Beating Degree}

The p-value of $A$ in Table 4 is 0.0171 , which represents $A$ was significant to model response. Based on the p-values of $A, B, C$, and $D$ from Table 4 , the sequence for the 4 factors influencing initial beating degree was $A>B>C>D$, that is, stalk size $>$ soaking time $>$ working temperature > processing speed. 
The length of the corn straw skin was the primary factor affecting the initial beating degree of the straw fiber. As the short straw skin was damaged to a large extent in the early crushing process, it was easier to be torn after entering the stalk fiber preparation machine, which generated more fine fibers, and too many fine fibers in the solution lead to poor water filtration performance, and the initial beating degree was high.

The p-values of the corresponding regression model for $B C$ and $C D$ were 0.0188 and 0.0329 , respectively, which indicated that factors refer to the cross terms had significant interaction influence on initial beating degree.

\section{Influences of Factors on the Fiber Aspect Ratio}

As shown in Table 5, the p-values of $A$ and $D$ were 0.0016 and 0.0012 , respectively, which indicated that $A$ and $D$ were highly significant relative to the response. Based on the p-values of $A, B, C, D$ from variance analysis in Table 5, the sequence for the 4 factors influencing the available fiber ratio was $D>A>C>B$, that is, processing speed $>$ stalk size $>$ soaking time $>$ working temperature $>$ processing speed.

The working speed of the stalk fiber preparation machine was the primary factor that affected the fiber length-width ratio. Because of the slower processing speed of the machine, longer processing time of the fiber was required. This indicated greater probability of the fiber being divided into individual fibers and greater probability of the reduction in fiber length.

The p-values of the corresponding regression model for $A C$ and $C D$ were 0.0317 and 0.0045 respectively, which indicated that factors were related to the cross terms respectively had significant and highly significant interactions, influencing the aspect ratio of the fiber produced.

Table 3. Variance Analysis of Regression Model of Available fiber ratio

\begin{tabular}{|c|c|c|c|c|c|c|}
\hline \multirow{7}{*}{ Source } & $\begin{array}{c}\text { Sum of } \\
\text { Squares }\end{array}$ & $\begin{array}{c}\text { Degrees of } \\
\text { Freedom }\end{array}$ & $\begin{array}{c}\text { Mean } \\
\text { Square }\end{array}$ & F value & $\begin{array}{c}\text { p values of } \\
\text { Significant } \\
\text { Levels }\end{array}$ \\
\cline { 2 - 7 } & Model & 0.1934 & 10 & 0.02 & 3.45 & $0.0058^{* *}$ \\
\cline { 2 - 7 } & $A$ & 0.0000 & 1 & 0.00 & 0.00 & 0.9862 \\
\cline { 2 - 7 }$y_{1}$ & $C$ & 0.0215 & 1 & 0.02 & 3.83 & 0.0615 \\
\cline { 2 - 7 } & $D$ & 0.1171 & 1 & 0.12 & 20.86 & $0.0001^{* *}$ \\
\cline { 2 - 7 } & $A B$ & 0.0003 & 1 & 0.00 & 0.06 & 0.8159 \\
\cline { 2 - 7 } & $A C$ & 0.0002 & 1 & 0.01 & 0.90 & 0.3514 \\
\cline { 2 - 7 } & $A D$ & 0.0036 & 1 & 0.00 & 0.04 & 0.8397 \\
\cline { 2 - 7 } & $B C$ & 0.0094 & 1 & 0.01 & 1.68 & 0.4315 \\
\cline { 2 - 7 } & $B D$ & 0.0332 & 1 & 0.03 & 5.91 & $0.02266^{*}$ \\
\cline { 2 - 7 } & $C D$ & 0.0030 & 1 & 0.00 & 0.53 & 0.4729 \\
\cline { 2 - 7 } & Residual & 0.1403 & 25 & 0.01 & & 0.3180 \\
\cline { 2 - 7 } & Lack of Fit & 0.0884 & 14 & 0.01 & 1.34 & \\
\cline { 2 - 7 } & Pure Error & 0.0519 & 11 & 0.00 & & \\
\cline { 2 - 7 } & Core Total & 0.3337 & 35 & & & \\
\hline
\end{tabular}

Notes: **Highly significant $(p<0.01)$;and *significant $(p<0.05)$ 
Table 4. Variance Analysis of Regression Model of Initial Beating Degree

\begin{tabular}{|c|c|c|c|c|c|c|}
\hline \multirow{16}{*}{$y_{2}$} & Source & $\begin{array}{l}\text { Sum of } \\
\text { Squares }\end{array}$ & $\begin{array}{c}\text { Degrees of } \\
\text { Freedom }\end{array}$ & $\begin{array}{l}\text { Mean } \\
\text { Square }\end{array}$ & $F$ value & $\begin{array}{c}P \text { values of } \\
\text { Significant } \\
\text { Levels }\end{array}$ \\
\hline & Model & 43.82 & 10 & 4.38 & 2.87 & $0.0158^{*}$ \\
\hline & $A$ & 9.97 & 1 & 9.97 & 6.52 & $0.0171^{*}$ \\
\hline & $B$ & 5.31 & 1 & 5.31 & 3.47 & 0.0742 \\
\hline & $C$ & 4.00 & 1 & 4.00 & 2.62 & 0.1183 \\
\hline & $D$ & 0.28 & 1 & 0.28 & 0.18 & 0.6715 \\
\hline & $A B$ & 2.21 & 1 & 2.21 & 1.44 & 0.2408 \\
\hline & $A C$ & 0.26 & 1 & 0.26 & 0.17 & 0.6816 \\
\hline & $A D$ & 0.22 & 1 & 0.22 & 0.14 & 0.7081 \\
\hline & $B C$ & 9.64 & 1 & 9.64 & 6.31 & $0.0188^{*}$ \\
\hline & $B D$ & 4.14 & 1 & 4.14 & 2.71 & 0.1121 \\
\hline & $C D$ & 7.79 & 1 & 7.79 & 5.10 & $0.0329^{*}$ \\
\hline & Residual & 38.19 & 25 & 1.53 & & \\
\hline & Lack of Fit & 26.93 & 14 & 1.92 & 1.88 & 0.1491 \\
\hline & Pure Error & 11.26 & 11 & 1.02 & & \\
\hline & Core Total & 82.00 & 35 & & & \\
\hline
\end{tabular}

Notes: ${ }^{*}$ Highly significant $(p<0.01)$; and ${ }^{*}$ significant $(p<0.05)$

Table 5. Variance Analysis of Regression Model of Fiber Aspect Ratio

\begin{tabular}{|c|c|c|c|c|c|c|}
\hline \multirow{16}{*}{$y_{3}$} & Source & $\begin{array}{l}\text { Sum of } \\
\text { Squares }\end{array}$ & $\begin{array}{c}\text { Degrees of } \\
\text { Freedom }\end{array}$ & $\begin{array}{l}\text { Mean } \\
\text { Square }\end{array}$ & $F$ value & $\begin{array}{l}P \text { values of } \\
\text { Significant } \\
\text { Levels }\end{array}$ \\
\hline & Model & 165.92 & 10 & 16.59 & 4.87 & $0.0006^{* *}$ \\
\hline & $A$ & 42.59 & 1 & 42.59 & 12.50 & $0.0016^{\star \star}$ \\
\hline & $B$ & 5.37 & 1 & 5.37 & 1.58 & 0.2209 \\
\hline & $C$ & 5.93 & 1 & 5.93 & 1.74 & 0.1990 \\
\hline & $D$ & 45.76 & 1 & 45.76 & 13.43 & $0.0012^{\star *}$ \\
\hline & $A B$ & 3.10 & 1 & 3.10 & 0.91 & 0.3494 \\
\hline & $A C$ & 17.65 & 1 & 17.65 & 5.18 & $0.0317^{*}$ \\
\hline & $A D$ & 10.47 & 1 & 10.47 & 3.07 & 0.0919 \\
\hline & $B C$ & 0.49 & 1 & 0.49 & 0.14 & 0.7070 \\
\hline & $B D$ & 1.43 & 1 & 1.43 & 0.42 & 0.5232 \\
\hline & $C D$ & 33.13 & 1 & 33.13 & 9.72 & $0.0045^{\star *}$ \\
\hline & Residual & 85.17 & 25 & 3.41 & & \\
\hline & Lack of Fit & 42.72 & 14 & 3.05 & 0.79 & 0.6657 \\
\hline & Pure Error & 42.45 & 11 & 3.86 & & \\
\hline & Core Total & 251.09 & 35 & & & \\
\hline
\end{tabular}

Note: **Highly significant $(P<0.01)$; and ${ }^{*}$ significant $(P<0.05)$ 


\section{Significant Influence of Interaction Factors on Reponses}

Response surface diagrams are shown in Figs. 1 to 3.

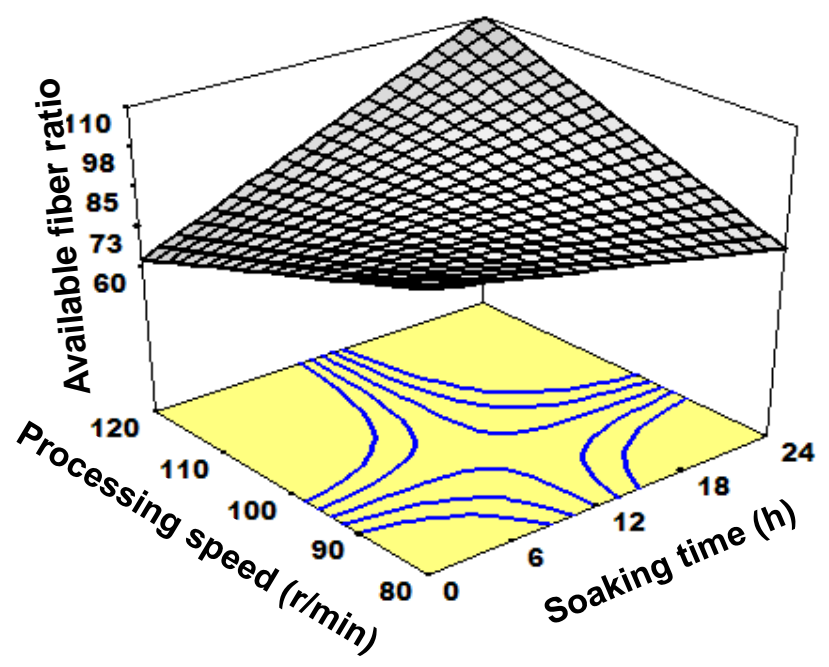

Fig. 1. Response surface plot of significant factors on available fiber ratio

Figure 1 indicates the interactions between the soaking time and processing speed. The conditions used were as follows: stalk size, $7 \mathrm{~cm}$; and working temperature, $70{ }^{\circ} \mathrm{C}$. During short soaking times, the available fiber ratio and processing speed were negatively correlated due to the presence of water in rind of corn stalk and in machine. There was almost no free water in the machine, water inside of corn stalk rind was too little to swell the plant cell, there was still strong fiber bonding, which led to a low degree of fiber separation. The fiber percentage was low in mesh number less than $10 \mathrm{~mm}$. With the increasing of processing speeds, the rind fiber did not have enough time to cut into fine fiber. During long soaking time, the available fiber ratio and processing speed were positively correlated, which might be attributed to water in rind of corn stalk and in machine, fiber could be separated into fine fiber.

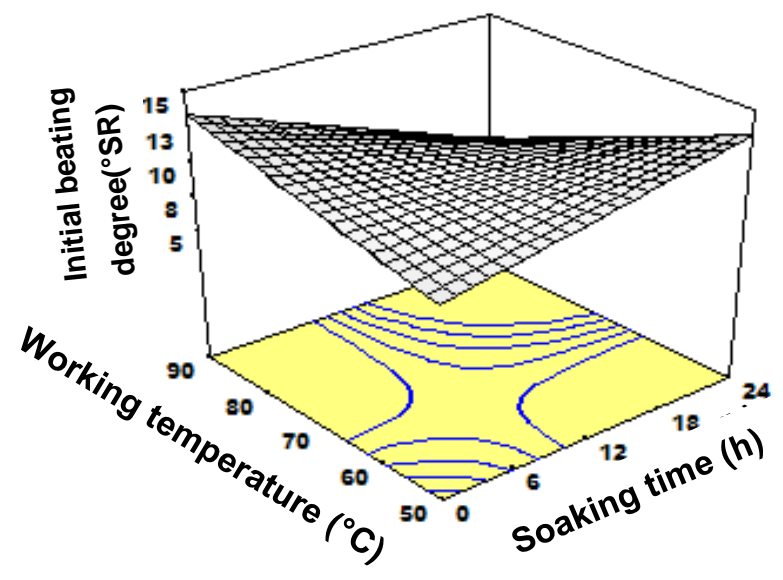

a

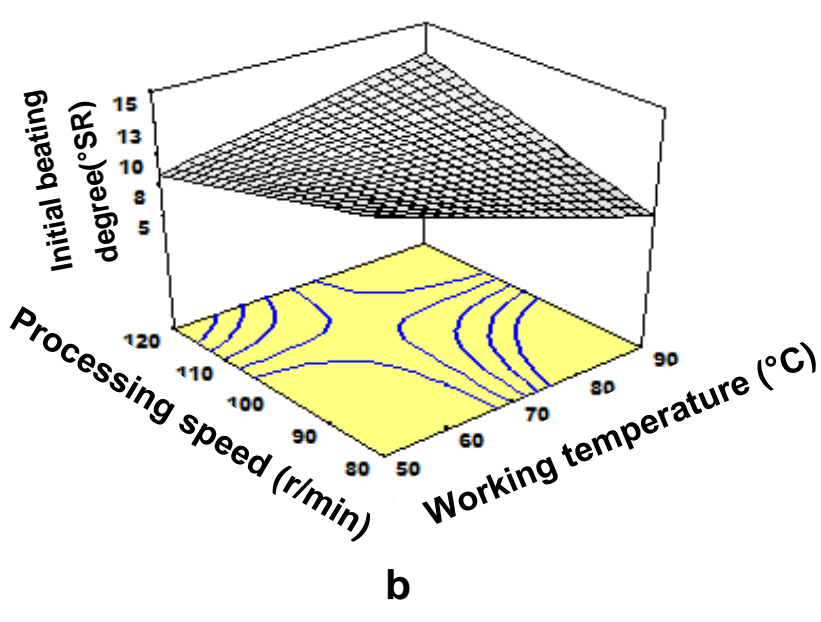

Fig. 2. Response surface plot of significant factors on initial beating degree

Figures $2 \mathrm{a}$ and $2 \mathrm{~b}$ indicate interactions between the soaking time and working temperature, as well as interactions between the working temperature and processing speed 
to the initial beating degree, respectively. When the condition used was as follows: the stalk size, $7 \mathrm{~cm}$; processing speed, $100 \mathrm{r} / \mathrm{min}$, in the condition of short soaking time, the initial beating degree and working temperature were positively correlated. With increasing working temperature the fiber cutting might be accelerated and thus the fibers were more fibrillated. In contrast, in the long soaking time, the initial beating degree and working temperature were negatively correlated. Water played an important role in the process; it accelerated the fiber being separated into thinner single fiber, but it decelerated the fiber fibrillation and cut into cellulosic fines.

When the condition was as follows: the stalk size was $7 \mathrm{~cm}$ and soaking time was $12 \mathrm{~h}$, in the condition of low working temperature, the initial beating degree and processing speed were negatively correlated. Thus, there was low content of water for steam generation; hence the bound water in fiber cells immediately changed into steam. This damaged the fiber cell walls and led to a low degree of fiber fibrillation. On the contrary, in the condition of high working temperature, with the increasing processing speed, the steam played an important role in the process, such that there was high cutting opportunity between damaged fiber, and thus there was high degree of fibrillation.

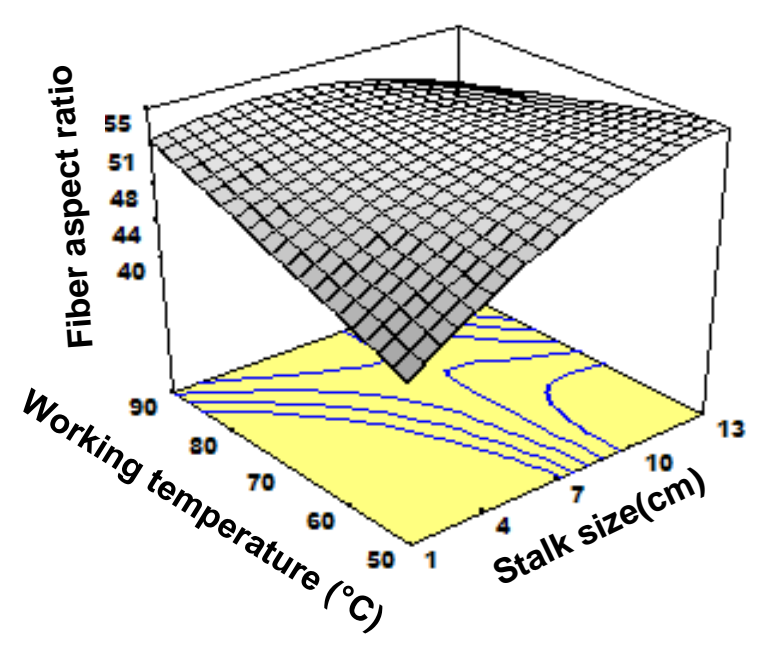

a

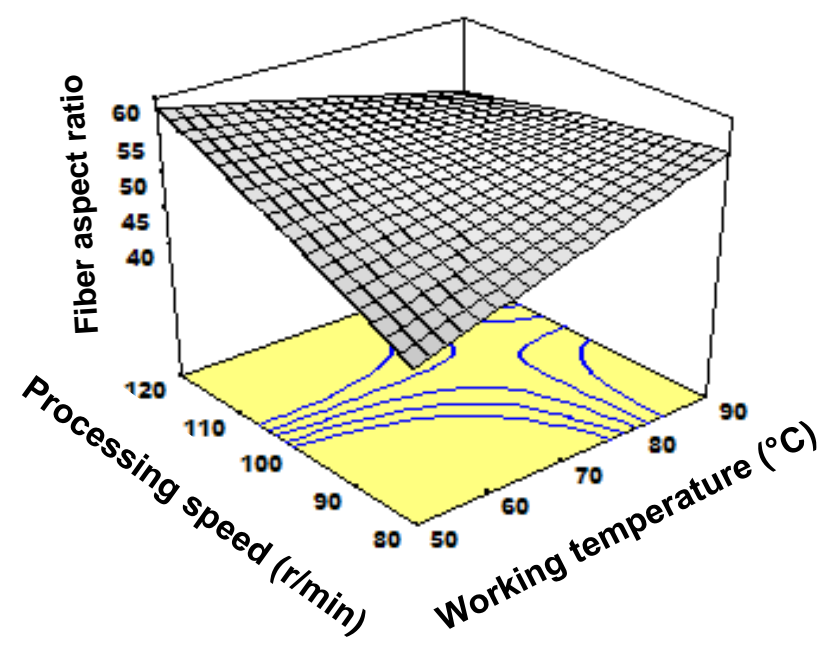

b

Fig. 3. Response surface plot of significant factors on fiber aspect ratio

Figures $3 \mathrm{a}$ and $3 \mathrm{~b}$ indicate interactions between the stalk size and the working temperature, as well as interactions between working temperature and processing speed to the fiber aspect ratio, respectively. When the condition used was as follows: the processing speed was $100 \mathrm{r} / \mathrm{min}$ and the soaking time was $12 \mathrm{~h}$, with short stalk size, the fiber aspect ratio and working temperature were positively correlated. Thus, there was week fiber bonding, with increasing working temperature, then water changed into steam. This energy accelerated the fibrillation and resulted in cellulosic fines. In the condition of long stalk size, high working temperature separated long stalk size into short stalk size, there was high cut opportunity, and the low energy made fiber into single fine fiber.

When the condition was as follows: the stalk size was $7 \mathrm{~cm}$ and soaking time was $12 \mathrm{~h}$, the fiber aspect ratio and working temperature were positively correlated. In the condition of low working temperature, with the increasing processing speed, the energy accelerated fibrillation and resulted in the generation of cellulosic fines. In the condition of 
high working temperature, the large part of energy might be used to cut fiber shorter, small part of energy might be used to accelerate the fibrillation.

\section{Optimization of Parameters and Verification Test}

In order to optimize the parameters experimentally, the following principles were adopted: economically effective, environmental friendly, and energy-saving stalk utilization; improved process simplicity; increased available fiber ratio, initial beating degree, and the fiber aspect ratio. The following process parameters of various factors and expected values of the performance indicators of target responses were set: available fiber ratio was higher than $95 \%$, initial beating degree was greater than $11^{\circ} \mathrm{SR}$, and fiber aspect ratio was more than 50. The process parameters of various factors were all in the range of experimental design, and the optimized resultsare shown in Fig. 4. The combination of various factors used was: $8 \mathrm{~cm}$ to $13 \mathrm{~cm}$ stalk size, $18 \mathrm{~h}$ of soaking time, $60{ }^{\circ} \mathrm{C}$ for the working temperature, and 98 to $112 \mathrm{r} / \mathrm{min}$ for the processing speed.

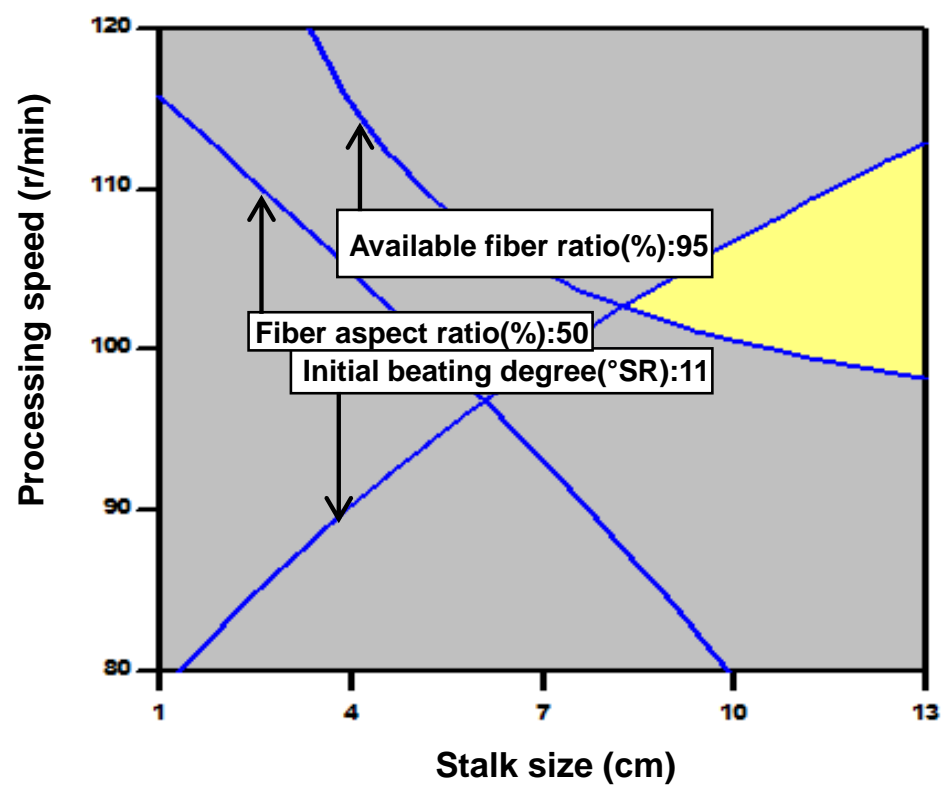

Fig. 4. Optimum analysis plot, with the conditions of $18 \mathrm{~h}$ for the soaking time and $60^{\circ} \mathrm{C}$ for the working temperature

In order to confirm the results of optimization, ten groups of verifying tests were conducted using the optimum process parameter combination given above, the average values were calculated, and the values of factors were measured, respectively. The conclusions were as follows: The available fiber ratio was $95.8 \%$, the initial beating degree was $11.6{ }^{\circ} \mathrm{SR}$, and the average fiber aspect ratio was 56.2, which indicated that the regression models and the test parameters were reliable. The objective functions of the regression equations were accurately predictive. The validity of the model was thus confirmed, when the verification value and optimized value fitted well. The test thus provided a valuable reference model. The effect of tensile index on technological parameters was not taken into consideration in this paper, although it is one of key factors and might be focused upon in future studies. 


\section{CONCLUSIONS}

1. Among the factors selected in the experiment, the working temperature had highly significant effects on available fiber ratio, the stalk size had significant effects on initial beating degree, the stalk size and the processing speed had highly significant effects on fiber aspect ratio, respectively.

2. The optimal parameter combination for stalk size, soaking time, working temperature, and processing speed were $8 \mathrm{~cm}$ to $13 \mathrm{~cm}, 18 \mathrm{~h}, 60{ }^{\circ} \mathrm{C}$, and 98 to $112 \mathrm{r} / \mathrm{min}$, respectively.

\section{ACKNOWLEDGMENTS}

The authors acknowledge funding from the National Natural Science Foundation Youth Fund of China (31701311) and the National Key Research and Development Plan (2018YFD0201004). They also acknowledge the Wang De-fu team of Northeast Agricultural University in China.

\section{REFERENCES CITED}

Byrd, M., and Hurter, R. (2005). "A simplified pulping and bleaching process for pith containing nonwoods: Trials on whole corn stalks," in: TAPPI Engineering, Pulping and Environmental Conference, Philadelphia, PA, USA, pp. 28-31.

Chen, Z. G., and Wang, D. F. (2017). "Power consumption for core scraping in the separation of rind-pith from corn stalk," BioResources 12(1), 1300-1316.

DOI: 10.15376/biores.12.1.1300-1316

Delgado-Aguilar, M., Vilaseca, F., Tarrés, Q., and Julian, F. (2018). "Extending the value chain of corn agriculture by evaluating technical feasibility and the quality of the inter phase of chemo-thermo mechanical fiber from corn stover reinforced polypropylene biocomposites," Composites Part B-Engineering 137, 16-22.

DOI:10.1016/j.compositesb.2017.11.006

Fatehi, P., Ryan, J., and Ni, Y. (2013). "Adsorption of lignocelluloses of model prehydrolysis liquor on activated carbon," Bioresource Technology 131, 308-314. DOI:10.1016/j.biortech.2012.12.156

FitzPatrick, M., Champagne, P., Cunningham, M. F., and Whitney, R. A. (2010). "A biorefinery processing perspective: Treatment of lignocellulosic materials for the production of value-added products," Bioresource Technology 101(23), 8915-8922. DOI: $10.1016 /$ j.biortech.2010.06.125

GB/T 24325(2009). "Pulp-laboratory beating - Valley beater method," Standardization Administration of China, Beijing, China.

GB/T 3332 (2004). "Schopper-Riegler method," Standardization Administration of China, Beijing, China.

GB/T10336 (1989). "Conventional optical microscopy assays," Standardization Administration of China, Beijing, China.

Haapala, T., Palonen, P., Korpela, A., and Jukka, A. (2014). "Feasibility of paper mulches in crop production: A review," Agricultural and Food Science 23, 60-79. DOI: $10.23986 /$ afsci.8542 
Han, Y. J. (2011). Study on the Technology and Performance of Preparing Plant Fiber Functional Plastic Film from Rice Straw, Ph.D. Dissertation, Northeast Agricultural University, Harbin.

He, X., Wang, D. F., Kong, F. T., and Yu, K. Q. (2016). "Pelletizing properties of corn stalk rind," Journal of Renewable and Sustainable Energy 8(1), 1-11. DOI: $10.1063 / 1.4940660$

Kadam, K. L., and McMillan, J. D. (2003). "Availability of corn stover as a sustainable feedstock for bioethanol production," Bioresource Technology 88(1), 17-25. DOI:10.1016/S0960-8524(02)00269-9

Liu, H. Y., Chen, H. T., Hou, L., and Zhang, Y. (2017). "Optimal design and experiment for raw material supply system of d200 stalk fiber extruder," Transactions of the Chinese Society of Agricultural Engineering 48(3), 92-98.

Reddy, N., and Yang, Y. (2005). "Biofibers from agricultural byproducts for industrial applications," Trends in Biotechnology 23(1), 22-27.

DOI: $10.1016 /$ j.tibtech.2004.11.002

Saijonkari-Pahkala, K. (2008). "Non-wood plants as raw material for pulp and paper," Agricultural and Food Science 10(Suppl.), 1-101.

Sain, M., and Panthapulakkal, S. (2005). "Bioprocess preparation of wheat stalk fibers and their characterization," Industrial Crops and Products 23, 1-8.

Wang, N., and Chen, H. Z. (2013). "Manufacture of dissolving pulps from cornstalk by novel method coupling steam explosion and mechanical carding fractionation," Bioresource Technology 139, 59-65. DOI:10.1016/j.biortech.2013.04.015

Zhong, W., Zhang, Z., Luo, Y., Sun, S., Qiao, W., and Xiao, M. (2011). "Effect of biological pretreatments in enhancing corn stalk biogas production," Bioresource Technology 102(24), 77-82. DOI:10.1016/j.biortech.2011.09.077

Zhang, Y., Chen, H. G., Dun, G. Q., Han, Y. J., and Chen, H. T. (2014). "Study on the stalk fiber films mulching cultivation green pepper," Journal of Northeast Agricultural University 45(11), 95-100.

Article submitted: October 19, 2019; Peer review completed: December 8, 2019; Revised version received: December 10, 2019; Accepted: December 14, 2019; Published:

December 17, 2019.

DOI: 10.15376/biores.15.1.923-934 